recreation convened a multi-agency key stakeholder partnership to develop a whole-of-sport overarching safety plan and accompanying practical safety guidelines. The aim was to assist state sporting organisations (SSOs) and community sports providers to adopt a strategic, evidence-based and sustainable approach to safety. Previous research had identified that higher-order sports administration bodies (eg, SSOs) have a relatively unsophisticated approach to facilitating the adoption of new policies and practices at the community level, focusing on information distribution and awareness raising. In an endeavour to enhance the sustained use of safety guidelines, we developed a strategic approach to diffusion based on the Diffusion of Innovations theory of EM Rogers. This paper discusses the development of a strategic approach to diffusion of safety-related guidelines in the sports sector, including concepts and principles such as the innovation-decision process, the role of opinion leaders and change-agents, use of mass media and interpersonal communication channels, the adopters perceptions of the characteristics of an innovation, and attributes of early and late adopters of innovations.
0174 A STRATEGIC APPROACH TO DISSEMINATING

\section{SPORTS SAFETY GUIDELINES: AN APPLICATION OF THE DIFFUSION OF INNOVATIONS THEORY FOR NEW SOUTH WALES, AUSTRALIA}

A Donaldson, R G Poulos* Correspondence: School of Human Movement and Sports Sciences, University of Ballarat, 18A Beaconsfield Road, Hawthorn East, Victoria 3123, Australia

\subsection{6/ip.2010.029215.174}

Safety guidelines and risk management processes have little impact if no one knows about them, decides to use them, uses them in the way they are intended, or uses them over a long period of time. There has been recent interest in facilitating the translation of evidence-based sports injury prevention interventions into sustained safety policy and practice in real-world community sports settings. In 2009, the New South Wales state governments department of sport and 